\title{
O PAPEL DOS ADVÉRBIOS FOCALIZADORES NA MANUTENÇÃO DA ORDEM LINEAR DOS CONSTITUINTES DA ORAÇÃO*
}

Edson Rosa Francisco de Souza**

RESUMO: O objetivo deste trabalho é descrever, com base na Gramática Funcional de Dik, a funcionalidade dos advérbios focalizadores (exatamente, principalmente, justamente, somente, também) e sua possibilidade de co-ocorrência com a ordem especial de constituintes no Português Falado do Brasil, de acordo com suas funções sintáticas, semânticas e pragmáticas. Em outras palavras, o nosso objetivo é verificar se o uso dos advérbios focalizadores constitui um mecanismo utilizado pelo falante para preservar a ordem linear dos constituintes da oração, isto é, se o uso desses mecanismos está relacionado à manutenção da ordem canônica da oração.

PALAVRAS-CHAVE: Funcionalismo, Advérbios Focalizadores, Ordem de Palavras, Co-ocorrência de Estratégias de Focalização.

ABSTRACT: Under Dik's Functional Grammar, the aim of this research is to describe the functionality of focus adverbs (exactly, mainly, actually, justly, also, only) and their possibility of co-occurrence with word order in Spoken Brazilian Portuguese, according to their syntactic, semantic and pragmatic functions. In other words, our principal goal is to verify if the use of the focus adverbs constitutes a mechanism used by the speaker to preserve the lineal word order of the clause, that is, if the use of these focus mechanisms is related to the maintenance of the canonical order of the clause.

KEYWORDS: Functionalism, Focus Adverbs, Word Order, Cooccurrence.

*Neste artigo, apresento algumas questões da minha Dissertação de mestrado "Os advérbios focalizadores no português falado do Brasil: uma abordagem funcionalista", desenvolvida sob a orientação da $\operatorname{Prof}^{a} \operatorname{Dr}^{\mathrm{a}}$ Marize M. Dall'Aglio Hattnher - IBILCE/UNESP, com o apoio da FAPESP (Proc. 02/12621-5). 
*Doutorando em Lingüística (IEL/UNICAMP)

\section{PALAVRAS INICIAIS}

Centrado na perspectiva funcionalista de autores como Dik (1989; 1997) e Hengeveld (1997) ${ }^{1}$, o presente trabalho tem por objetivo descrever a funcionalidade dos advérbios focalizadores (exatamente, principalmente, justamente, somente, também etc.) e sua coocorrência com a ordem especial de constituintes no português falado do Brasil (PB). Em termos gerais, o nosso objetivo é analisar as razões sintáticas, semânticas e pragmáticas que favorecem o uso desses mecanismos de focalização na atribuição de Foco a determinados constituintes da oração. Dessa maneira, por estar situado no universo da ordem de palavras, o nosso objetivo maior é verificar se o uso desses advérbios constitui um mecanismo utilizado pelo falante para focalizar e, ao mesmo tempo, preservar a ordem linear dos constituintes na oração, isto é, se esse uso está relacionado à manutenção da ordem canônica dos termos da oração. Num segundo momento, a nossa tarefa é investigar por que esse mecanismo de focalização co-ocorre com uma outra estratégia, se a ordem especial de constituintes, bastante recorrente entre as línguas do mundo, por si só já bastaria para marcar a função pragmática Foco.

Nesse contexto, considerando a importância da proeminência prosódica no Inglês, que é, segundo Van Valin \& LaPolla (1997), uma língua de estrutura sintática rígida e estrutura de foco flexível, nossa expectativa é a de que os advérbios focalizadores ( $\mathrm{AdvF}$ ) exerçam no $\mathrm{PB}$ a mesma função que a proeminência prosódica exerce no Inglês, que é a de focalizar qualquer constituinte da oração sem alterar sua ordem.

\section{NOTAS SOBRE OS ADVÉRBIOS FOCALIZADORES}

Em um trabalho sobre os advérbios, Ilari et alii (1990) e Ilari (1992) identificam a focalização como uma das muitas funções 
exercidas por essa classe, considerada extremamente heterogênea (cf. MACKENZIE, 2001; HENGEVELD, 1997). Advérbios como exatamente, justamente e principalmente, que "chamam a atenção para o papel semântico de uma expressão próxima” (ILARI $e t$ alii, 1990, p.76) ou "aplicam a algum constituinte um carimbo de 'conferido', sugerindo que o locutor está de posse dos resultados de alguma verificação” (id. ibid.) são agrupados ao lado de advérbios que indicam inclusão ou exclusão, como também e só, por "darem destaque a um constituinte da sentença”. $\mathrm{Na}$ ocorrência (1), por exemplo, o advérbio principalmente exerce a função de focalizador, atuando sobre um satélite $\mathrm{s}_{2}$ com a função semântica de Lugar (em Altamira).

(1) mas em alguns dos desenhos das cavernas principalmente

em Altamira... há uma fidelidade...

linear à natureza

que consegue mostrar os animais:: (EF/RJ/405:395)

Como se pode observar na ocorrência acima, o satélite em negrito constitui o escopo do advérbio em questão. Para o discurso, a expressão "em Altamira" caracteriza uma informação nova (CHAFE, 1976), o que justifica a atribuição da função pragmática Foco a esse constituinte. Ao fazer isso, o emissor presume que o destinatário possui uma parte de informação correta, mas também acredita numa outra que está incorreta. Contudo, focalizar uma informação que o falante considera mais importante não é, a nosso ver, a única razão para o grande número de $\mathrm{AdvFs}$ no $\mathrm{PB}$. Assim, sem perder de vista o nível sintático da oração, lugar em que se situa um dos principais objetivos do nosso trabalho, pode-se constatar que a maior parte dos estudos publicados sobre Foco, em especial, sobre o funcionamento dos $\mathrm{AdvFs}$, não procura questionar a relação existente entre a estrutura de foco e a estrutura sintática. É claro que, para muitos autores funcionalistas e gerativistas, o Foco pode ser marcado pela ordem especial de constituintes, no entanto, 
o que nos interessa saber é o que os AdvFs fazem de diferente na estrutura da oração que as outras estratégias de focalização não fazem. Como dito anteriormente, a nossa expectativa é a de que o funcionamento desses AdvFs possa ser comparado ao da proeminência prosódica no Inglês, que focaliza um elemento sem alterar a ordem da oração (cf. Van Valin; Lapolla, 1997), assim como em (2) e (3):

(2) a. DANA sent the book to Leslie yesterday. $D A N A$ enviou o livro para Leslie ontem.

b. Dana sent the book to LESLIE yesterday. Dana enviou o livro para LESLIE ontem.

(3) a. e você vai num país desenvolvido não bá aquele que não trabalhe... que não faça alguma coisa... até os velbos... sujeito de setenta... setenta e cinco anos está fazendo alguma coisa... (D2/RJ/355:1040)

b. eu por exemplo estou acostumada a comer só verdura e carne...eu tive muita dificuldade em me alimentar lá [no norte]... (DID/RJ/328:128)

Como se vê, em ambas as línguas, a ordem SVO da oração mantém-se inalterada, sendo o Foco marcado ora pela proeminência prosódica ora pelos AdvFs. Em (2), o sujeito e o objeto da oração são focalizados por meio da proeminência prosódica, sem provocar nenhum tipo de reestruturação sintática. Já em (3), o sujeito e o objeto são focalizados por meio de dois advérbios distintos (até e só), apresentando, assim, um comportamento bastante semelhante ao da proeminência prosódica no Inglês, em que as duas estratégias focalizam um constituinte sem alterar a ordem canônica da oração.

\section{ARCABOUÇO TEÓRICO}


Segundo o ponto de vista funcional, uma língua natural deve ser considerada, primeiramente, "como um instrumento de interação social por meio do qual seres humanos podem se comunicar uns com os outros e, assim, influenciar mutuamente as atividades mentais e práticas" (DIK, 1980, p.1). Nesse sentido, o funcionalismo ${ }^{2}$ considera que "a situação comunicativa motiva, restringe, explica ou determina a estrutura gramatical" (NICHOLS, 1984, p.97). Com base nesse arcabouço teórico, Dik (1989) assinala que a atribuição de Foco a um determinado constituinte da oração é o que justifica, por exemplo, a presença de uma ordenação especial dos termos da oração ou a utilização de $\mathrm{AdvFs}$, uma vez que esses mecanismos constituem dois tipos especiais de estratégias de $\mathrm{Foco}^{3}$ utilizadas pelo falante para colocar em destaque uma dada informação que ele considera importante para ser integrada à informação pragmática do ouvinte (BRAGA, 1999).

Por essas e outras colocações, Halliday (1985) destaca que a gramática funcional procura concentrar a atenção nos usuários e nos usos da língua, mediante uma valorização do receptor, do emissor e da variação lingüística no quadro gramatical. De acordo com Neves (1997), no modelo teórico de Dik (1989), os componentes sintáticos e semânticos encontram-se integrados a uma teoria pragmática, que, por sua vez, envolve a intervenção:

a) dos papéis envolvidos nos estados de coisas designados pelas predicações (funções semânticas);

b) da perspectiva selecionada para apresentação dos estados de coisas na expressão lingüística (funções sintáticas);

c) do estatuto informacional dos constituintes dentro do contexto comunicativo em que eles ocorrem (funções pragmáticas).

Trata-se de uma teoria que procura, segundo Gebruers (1984, apud NEVES, 1997), oferecer "um quadro para a descrição científica 
da organização lingüística em termos das necessidades pragmáticas da interação verbal, na medida em que isso é possível” (p. 349). Tendo em vista esse princípio, Dik $(1989 ; 1997)$ destaca que para se chegar às expressões lingüísticas superficiais, são necessárias regras de colocação para atribuírem posições aos constituintes de uma dada estrutura subjacente. Essas regras, segundo o autor, obedecem a certos princípios que determinam as possíveis seqüências dos constituintes da oração. Assim, essa teoria de ordenação postula que cada língua apresenta um ou mais padrões funcionais, segundo o esquema geral em (4).

\section{(4) P2, P1 (V) S (V) O (V), P3}

A operação das regras de colocação ${ }^{5}$, segundo Dik (1989), ocorre de tal maneira que, em primeiro lugar, são alocados os constituintes que podem ocupar a posição P1, tais como palavrasQu, pronomes relativos e conectores subordinativos. Se nenhum constituinte desse tipo estiver presente, então, podem ser colocados em P1 constituintes com as funções pragmáticas de Foco (informação de maior saliência), Tópico (sobre o que se fala) ou Organizador de Cenário (situa o EsCo em relação às coordenadas de tempo, espaço e circunstância), proposta por Hannay (1991) e Bolkestein (1998), e investigada por Cucolo (2002) em seu trabalho sobre os satélites de nível 1 e 2, no português falado do Brasil. Dessa maneira, a ocorrência (5) abaixo indica um satélite $s_{2}$ de Lugar que exerce a função pragmática de Organizador de Cenário, responsável por situar o EsCo no quadro espacial (de lugar).

(5) Inf essejantar dançante... é assim vamos (lá)...eles ab...(...) então depois naquele jantar eles sorteiam outros coisas... uns:: quatro casais...para Organizarem outro...jantar (DID/POA/45:23) 
Assim sendo, para Neves (1994, p.109), qualquer abordagem funcionalista de uma língua natural, na verdade, tem como questão básica de interesse a verificação de como se obtém a comunicação com essa língua. Isso implica considerar as estruturas das expressões lingüísticas como configuradoras de funções, sendo cada uma das funções vista como um diferente modo de significação na oração. É por essa razão que autores como Dik (1989), Pezatti (1998) e Connolly (1998) assinalam que as expressões lingüísticas só podem ser devidamente compreendidas quando levadas em consideração as informações contextual e situacional disponíveis aos interlocutores no momento da interação, já que é durante esse processo em que muitas de suas propriedades (formais e funcionais) são codeterminadas.

\section{ORDENAÇÃO DOS CONSTITUINTES DA ORAÇÃO NA PRESENÇA DE ADVFS}

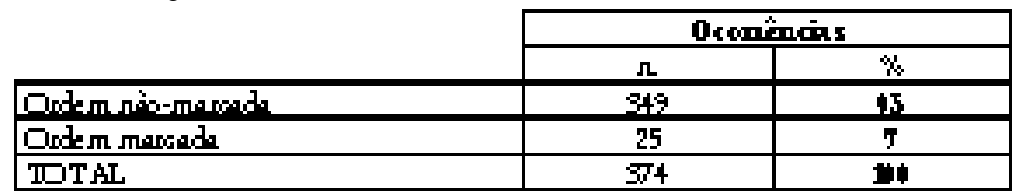

constituintes na oração, os dados ${ }^{6}$ foram analisados com o intuito de constatar se esses mecanismos de focalização estão de fato relacionados à manutenção da ordem canônica dos constituintes da oração. É o que se observa nos dados da tabela 1 a seguir:

Tabela 1: Ordenação dos constituintes da oração na presença de AdvFs

Conforme se pode verificar na tabela acima, quando analisada na presença de AdvFs, a ordem dos constituintes só se mostrou alterada em 7\% (25/374) das ocorrências contra 93\% (349/374) 
dos dados em que a ordem aparece não-marcada. A esse respeito, Dik (1989) assinala que uma construção é mais marcada à medida que é menos esperada no contexto, conseqüentemente, quando uma construção marcada ocorre, ela exige mais atenção. Sobre esse aspecto, Van Valin (1999), ao discutir questões de Foco, destaca que o russo, o polonês, o latim e o português são línguas que apresentam uma estrutura sintática menos rígida e, por isso, a ordenação especial de constituintes aparece como uma das estratégias mais utilizadas para a marcação de Foco, o que as difere do Inglês e do Toba Batak, língua do oeste da Indonésia, cujo Foco, em geral, é marcado pela proeminência prosódica ${ }^{7}$ em razão de sua ordenação sintática ser bem mais rígida. Segundo o autor, o que justifica a freqüência relativamente maior de proeminência prosódica no Inglês é o fato de essa estratégia não implicar nenhum tipo de reestruturação sintática para acomodar o Foco. Sendo assim, pode-se dizer que o uso expressivo de $\mathrm{AdvFs}$ no português brasileiro é, segundo Souza (2003b), perfeitamente comparável ao da proeminência prosódica no Inglês, tal como apontado por Martinez-Caro (1998) e Van Valin \& Lapolla (1997). Além disso, quando observada juntamente com os AdvFs, nota-se que a ordem dos constituintes da oração só é alterada em razão de algum interesse especial do falante, assim como mostram as ocorrências (6) e (7), que constituem claramente casos de objetos (A2) alocados na posição inicial da oração (P1), com a função pragmática Foco:

(6) Loc a gente faz uma comida que a (titia) chama de jardineira com couvinha mineira...faz couvinha mineira junta com... aquela couvinha bem partidinha bal faz na:...na...frigideira...depois põe em cima da carne e põe os legumes em cima... a gente usa muito por exemplo... esse tipo de comida aqui em casa... ela refoga...faz. ((confuso)) e ai a chuchu também a carne as/ por exemplo faz o que gente come com chama aqui em casa de trouxinha... a gente 
(DID/RJ/328:418)

(7) L1 eu tenho um conbecido...aliás...um amigo comum nosso que ele é especialista em comida internacional então vai faze (r) uma comida chinesa indiana...qualque(r) só falta música coisa... até incenso ele queima...ah... vesti(r) a rigor ambiental...só falta eu me (D2/POA/291:107)

Cabe notar que, em (6) e (7), os constituintes "chuchu" e "incenso", alocados na posição inicial da oração, servem à função pragmática Foco, cujo objetivo é ressaltar a informação relativamente mais importante no contexto. Nesses casos, o que leva o falante a focalizar, por meio de um advérbio, um constituinte já alocado na posição P1 da oração é a tentativa de impedir que certos constituintes focais sejam interpretados pelo ouvinte como Tópico ou Organizador de Cenário. Assim, para evitar que isso aconteça, o falante utiliza duas ou mais estratégias de focalização para deixar bem claro qual é a sua intenção comunicativa. Ou seja, a intenção do falante é o que explica, na nossa opinião, a dupla marcação de Foco nos dados do PB (AdvFs + Ordem especial).

Resumindo o que se disse sobre essas ocorrências, temos o seguinte:

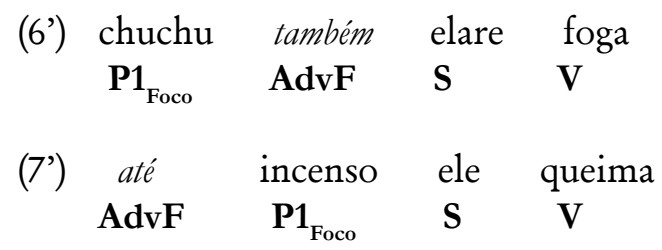

Tanto em (6') quanto em (7'), a ordem SVO dos constituintes da oração aparece alterada, com o objeto alocado no início da oração. Contudo ocorrências como essas correspondem, conforme já destacado, a apenas 7\% (25/374) do total dos dados, o que, 
por sua vez, comprova a nossa hipótese de que os advérbios constituem uma das principais estratégias utilizadas pelo falante para focalizar algum constituinte, sem que para isso seja necessário alterar a ordem não-marcada dos constituintes da oração. Nesse sentido, os casos de co-ocorrência de estratégias de focalização atrelados à ordem especial são, certamente, os únicos exemplares do corpus que se mostraram responsáveis pela mudança de ordem dos constituintes oracionais. No tocante aos demais tipos de coocorrência de estratégias (AdvF + Proeminência prosódica; $\mathrm{AdvF}$ + Construção clivada), a ordem dos termos da oração permaneceu inalterada, com o Foco sendo marcado pelas formas adverbiais.

Com relação à ordem não-marcada, as ocorrências (8) e (9) exemplificam casos em que os advérbios também e só focalizam, respectivamente, o sujeito "o Brasil” e o complemento verbal "o legume”, conforme se observa abaixo:

(8) L1

agora...você falou em problema estatal...não é? o Brasil também está caminhando pra economia estatal...e como eu leio ai nos jornais - a gente não é dessa área...né? quer dizer... desse setor - mas você vê... um absurdo o Brasil... a Companhia Siderúrgica Nacional no balanço apresentado... alto prejuizo...como é que uma companbia de aço...produtora...de...de...de aço...pode dar prejuízo? (D2/RJ/355:1140)

(9) Inf quando eu como muita coisa [...] ...bata::ta.. macarrão:::pão:: quando eu por um acaso...tiver comido isso de manha...à noite então eu faço um::um balanço...e procuro tirar as coisas as outras coisas que possam vir a engordar feijão então tudo aquilo arroz ai eu como só o legume realmente e a fruta...o que eu não posso realmente é deixar...de comer coisas salgadas à noite... (DID/RJ/328:18)

Nessas ocorrências, para acomodar a função pragmática Foco, 
a ordem dos constituintes da oração não sofre nenhum tipo de mudança, o que mais uma vez corrobora a nossa hipótese defendida ao longo do trabalho. Resumindo o que dissemos das ocorrências acima, temos o seguinte:

(8’) o Brasil também está caminhando para economia estatal $S_{\text {Foco }} \operatorname{AdvF}$ Aux V O

(9’)

$\begin{array}{cccc}\text { eu } & \text { como } & \text { só } & \text { o legume } \\ \mathbf{S} & \mathbf{V} & \mathbf{A d v F} & \mathbf{O}_{\text {Foco }}\end{array}$

Até mesmo em construções do tipo VS, a ordem dos termos da oração costuma se manter inalterada (não-marcada), assim como se verifica na ocorrência (10):

(10) Inf Brailowski não sei se... se esteve aqui foi Ba/Backaus... Jorge Demus... e tantos outros que têm aí que nem sei... mais outros pianistas que a gente foi...lembro quando o Rubinstein tocava mas estava CHEIO o:: . ..o teatro todo né?... até aquelas galerias o balcão de segunda a gente em PÉ... ahn:: nos corredores botaram cadeiras tudo... e depois veio também o Giglio não sei se vocês já...viram:: (DID/POA/45:591)

Em construções como essas, é natural que o sujeito venha posposto ao verbo da oração, principalmente naqueles casos em que P1 já estiver ocupada. Em (10), a ordem P1VS não sofre nenhum tipo de reestruturação sintática para marcar o Foco "o Giglio”. Segundo Pezatti (2003), pelo fato de ser uma língua SVO, o PB mostra-se relativamente rígido com relação à colocação dos argumentos sujeito, objeto e oblíquo (A1, A2 e A3), preservando geralmente o esquema P1SVO. Todavia, mostra-se mais acessível 
à alteração da ordem canônica com constituintes satélites, ou seja, constituintes lexicais opcionais que veiculam informação adicional a uma das camadas no modelo hierárquico da oração. A ocorrência (11) representa um caso de satélite (adjunto adverbial) alocado no início da oração, com a Função pragmática Foco ${ }^{8}$ :

(11) Inf e podendo inclusive...eleger...representantes....para que esses mesmos representantes...sejam...seus porta vozes... possam com isso propor... legislar fazer ver inclusive ao poder executivo... ver que determinadas classes...são carentes de determinadas...questões...e que só através desses representantes é que evidentemente se pode chegar... a um denominador comum...ou a uma solução... (DID/ $\mathrm{RE} / 131: 311)$

Em (11), verifica-se que, apesar de o satélite ser focalizado por meio do $\mathrm{AdvF}$ só e da clivada é que, ele não poderia estar em P1, visto que ela já está ocupada pelo constituinte-P ${ }^{9}$, representado pelo relator subordinativo que. Assim, o fato de ser Foco e não estar em P1 é uma das justificativas para a incidência de outras estratégias de Foco sobre o satélite, tais como o advérbio e a clivada. Em outros termos, tem-se:

(11') que só através desses representantes é que se pode chegar

P1 AdvF Pa Foco $_{\text {Cliv Aux V }}$

Nesse contexto, quando um falante opta, por exemplo, por alocar os constituintes adverbiais no início da oração, a ordem não-marcada dos satélites é alterada em favor de algum interesse pragmático. No entanto, quando o falante deseja focalizar algum constituinte sem alterar demasiadamente a ordem canônica da oração, ele faz uso dos AdvFs para tal tarefa. Em (11), diferentemente das ocorrências (6) e (7), a ordem não-marcada dos termos argumentais da oração (A1, A2 e A3) não sofre nenhum tipo 
de alteração; só o satélite de instrumento através desses representantes é alocado em Pa.

A ocorrência (12), abaixo, exemplifica um caso em que o Adv focaliza um satélite $\mathrm{s}_{1}$ com a função semântica de Beneficiário, alocado em sua posição não-marcada:

(12) L2 exatamente né? então vamos tentar:: () ver se conseguem

L1 isso

L2 agora é uma carreira muito boa principalmente para mulber (D2/SP/360:635)

Tanto em (11) quanto em (12), a ordem SVO da oração não sofre nenhuma alteração. Em (12), o satélite "para mulher", focalizado pelo Adv principalmente, encontra-se alocado em sua posição não-marcada, isto é, a posição final da oração ${ }^{10}$. No tocante ao princípio de ordenação do português, Cucolo (2002) e Pezatti (1998) acreditam que as alterações da ordem canônica dos constituintes da oração podem ser explicadas em função de razões pragmáticas e semânticas. Tendo trabalhado com essas mesmas funções, Martín Arista (1994) também assinala que é o componente pragmático que determina a ordem em que as estruturas prosódicas e sintáticas se sucedem, assim como a relação que se estabelece entre as mesmas.

Com base nos exemplos apresentados aqui, pôde-se verificar que para preservar a ordem não-marcada da oração recorre-se aos AdvFs. No nosso caso, a ordem SVO só é quebrada em função de algum interesse pragmático ou, mais especificamente, naqueles casos em que o $\mathrm{AdvF}$ co-ocorre com ordem especial para a marcação do Foco.

\section{CONSIDERAÇÕES FINAIS}

Como vimos, para a Gramática Funcional de Dik (1989), o Foco constitui a informação mais saliente ou importante que o 
falante deseja acrescentar ao conhecimento pragmático do ouvinte. Nesse sentido, o objetivo do falante ao focalizar, por exemplo, um satélite ou um constituinte qualquer, no interior da oração, por meio de $\mathrm{AdvFs}$, é fornecer informações que ele considera essenciais para o seu interlocutor. Nesse contexto, foi possível verificar que os AdvFs constituem a principal estratégia de focalização utilizada pelo falante para focalizar algum constituinte da oração, sem que para isso fosse necessário alterar a sua ordem para acomodar a Funcão Pragmática Foco. Isso confirma que o uso expressivo de AdvFs no português brasileiro é perfeitamente comparável ao da proeminência prosódica no Inglês, cuja função é marcar o Foco sem alterar a ordem canônica da oração para a mesma finalidade, tal como apontado por Martinez-Caro (1998) e Van Valin \& Lapolla (1997). No entanto, esse resultado aponta que o PB, diferentemente da classificação dada por Van Valin (2003), não apresenta uma estrutura sintática totalmente flexível.

No caso da co-ocorrência de estratégias de focalização, quando algum constituinte é alocado em uma posição especial, mesmo com a presença de AdvFs na oração, observou-se que a ordem não-marcada é alterada em favor de algum interesse comunicativo do falante. O total de 25 ocorrências com ordem marcada referese exclusivamente aos casos em que os AdvFs co-ocorrem com a ordem especial para marcar o Foco. Nesse sentido, por pressupor que a sua mensagem pudesse ser interpretada de forma equivocada pelo interlocutor, o falante procura lançar mão de outros mecanismos para reforçar que determinada informação deve ser entendida como Foco, e não como Tópico ou Organizador de Cenário, por exemplo (cf. SOUZA, 2004).

\section{NOTAS}

${ }^{1}$ Conforme Neves, o que se analisa na Gramática Funcional são as frases efetivamente realizadas, para cuja interpretação se atribui especial importância ao contexto, tanto verbal como não-verbal. 
${ }^{2}$ Sobre essa corrente teórica, pode-se dizer que a Escola Lingüistica de Praga, em voga nos anos 60 e 70, constitui o berço do funcionalismo atual. Nessa época, Mathesius (1970 apud FIRBAS,1974), visto como um dos principais representantes dessa corrente, já destacava, em seus trabalhos, que na comunicação as formas lexicais e gramaticais de uma língua são produzidas para servir a um propósito especial imposto sobre elas pelos falantes no momento da interação. Segundo Neves (2001), a Escola Lingüística de Praga é a designação que se dá a um grupo de estudiosos que começou a atuar antes de 1930, para os quais a linguagem, acima de tudo, permitia ao homem reação e referência à realidade extralingüística.

${ }^{3}$ Para Dik (1989), as funções pragmáticas intra-oracionais dizem respeito ao status informacional dos constituintes de uma oração em relação à situação comunicativa.

${ }^{4}$ Para Pezatti \& Camacho (1997), o padrão geral de ordenação para o PB é esquematizado por: P2, P1 (S) V (S) O X, P3, em que o X é usado para indicar a posição dos satélites adverbiais.

${ }^{5} \mathrm{P} 2$ e P3 são as posições reservadas, respectivamente, para Tema (Theme) e Antitema (Tail), e as vírgulas indicam pausas entoacionais.

${ }^{6}$ Os dados são provenientes do corpus mínimo do Projeto de Gramática do Português Falado (PGPF), de diferentes capitais brasileiras, a saber: São Paulo, Rio de Janeiro, Porto Alegre, Recife e Salvador.

${ }^{7} \mathrm{Em}$ estudo sobre o uso das estratégias de focalização, Brentan (2001) verificou que a proeminência prosódica, de fato, é a estratégia mais utilizada no Inglês para a marcação de Foco.

${ }^{8}$ Como constituintes da oração propriamente dita, estamos 
considerando apenas os termos argumentais (A1, A2, A3). Já os termos não-argumentais, típicos da predicação estendida, também são considerados, porém, apenas para se referir ao processo de coocorrência de estratégias de focalização.

9Segundo Cucolo (2002), ocorrências como (11), no entanto, mostram que o Português, assim como outras línguas, necessita de uma outra posição $(\mathrm{Pa})$ para alocar constituintes com uma função pragmática especifica, quando a P1 já estiver ocupada por um constituinte-P1.

${ }^{10}$ Para maiores esclarecimentos, conferir também o trabalho de Souza (2003a) sobre a focalização dos constituintes adverbiais no interior da oração.

\section{REFERÊNCIAS}

BOLKESTEIN, A. M. What to do with Topic and Focus? Evaluating pragmatic information. In: HANNAY, M., BOLKESTEIN, A. M. (Eds.). Functional Grammar and verbal interaction. Amsterdam: John Benjamins, p. 193-214, 1998.

BRAGA, M. L. Fala, escrita e estratégias de focalização. SériEncontros. Araraquara, ano XVI, n. 1, p. 281-298, 1999.

BRETAN, P. F. C. Estratégias marcadas de focalização no inglês e no português falado: análise contrastiva. São José do Rio Preto, p. 153, Dissertação (Mestrado em Estudos Lingüísticos). IBILCE/ UNESP, Universidade Estadual Paulista, 2001.

CHAFE, W. Givenness, contrastiveness, definteness, subject, topics and point of view. In: LI, C. (ed). Subject and topic. New York: Academic Press, 1976.

CONNOLLY, J. H. Information, situation semantics and Functional Grammar. In: HANNAY, M., BOLKESTEIN, A. 
M. (eds.). Functional Grammar and verbal interaction (Studies in Language Companion Series, 44.). Amsterdam: John Benjamins, p. 167-190, 1998.

CUCOLO, G. R. Os constituintes adverbiais de nível 1 e 2 em posição inicial da oração. São José do Rio Preto, p. 70, Dissertação (Mestrado em Estudos Lingüísticos). IBILCE/UNESP, Universidade Estadual Paulista, 2002.

DIK, S. C. Studies in Functional Grammar. New York: Academic Press, 1980.

. The theory of Functional Grammar I. Dordrecht: Foris, 1989.

. The theory of Functional Grammar II. New York: Mouton, 1997.

FIRBAS, J. Some aspects of the czechoslovac approach to problems of functional sentence perspective. In: DANES, F. (Ed.). Papers on functional sentence perspective. Prague: Academic Publishing of Academy of Sciences, p. 11-37, 1974.

HALLIDAY, M. K. An introduction to Functional Grammar. London: Arnold, 1985.

HANNAY, M. Pragmatic function assignment and word order variation in a Functional Grammar of English. Journal of Pragmatics, v. 16 (2),p. 131-155, 1991.

HENGEVELD, K. Adverbs in Functional Grammar. In: WOTJAK, G. Toward a Functional Lexicology. Tübingen: Niemeyer, p. 121-136, 1997.

ILARI, R. et al. Considerações sobre a posição dos advérbios. In: CASTILHO, A. T. Gramática do português falado. Campinas: 
Ed. UNICAMP/FAPESP, v. I, p. 63-141, 1990.

. Sobre advérbios focalizadores. In:

. Gramática do português falado. Campinas: Ed. da UNICAMP/FAPESP, v. II, p. 193-212, 1992.

MACKENZIE, J. L. Adverbs and adpositions: the Cinderela Categories of Functional Grammar. Revista Canária de Estudos Ingleses, v. 42, Tenerife, p. 119-135, 2001.

MARTÍN ARISTA, J. Funciones pragmaticas marcadas y no marcadas. Miscelánea. Zaragoza: Universidad de Zaragoza, v. 15, p. 391-404, 1994.

MARTÍNEZ-CARO, E. Parallel Focus in English and Spanish: evidence from conversation. In: HANNAY, M., BOLKESTEIN, A. M. (Eds.). Functional Grammar and verbal interaction. Amsterdam: Benjamins, 1998.

NEVES, M. H. M. A gramática funcional. São Paulo: Martins Fontes, 2001.

. A gramática de usos é uma gramática funcional. ALFA. São Paulo: Editora Unesp, v. 41, p. 15-24, 1997.

. Uma visão geral da gramática funcional. ALFA. São Paulo: Editora Unesp, v. 38, p. 109-128, 1994.

NICHOLS, J. 1984. Functional theories of grammar. Annual Review of Anthropology, v. 13, pp. 13; 97-117, 1984.

PEZATTI, E. G. A função pragmática Foco em expressões adverbiais, sob o enfoque funcionalista de DIK. In: III Congresso Internacional da ABRALIN. Faculdade de Letras/UFRJ, Rio de Janeiro, 2003. 
. Constituintes pragmáticos em posição inicial: distinção entre Tema, Tópico e Foco. ALFA. São Paulo: Editora Unesp, v. 42, pp. 133-150, 1998.

; CAMACHO, R. G. Aspectos funcionais da ordem de constituintes. D.E.L.T.A. São Paulo, v. 13, n. 2, p. 191-214, 1997.

SOUZA, E. R. F. Os advérbios focalizadores no português falado do Brasil: uma abordagem funcionalista. São José do Rio Preto, p. 175 Dissertação (Mestrado em Estudos Lingüísticos). IBILCE/ UNESP, Universidade Estadual Paulista, 2004.

. A focalização dos constituintes adverbiais no interior da oração. In: III Congresso Internacional da ABRALIN. UFRJ, Rio de Janeiro, 2003a.

. The behavior of focus adverbs in Brazilian Spoken Portuguese: a functional approach. In: The 2003 International 
165 